\title{
Environmental Interpretation: How to Communicate Persuasively 1
}

Kara N. Youngentob and Mark E. Hostetler²

\section{Interpreting the Environment}

Interpretation is a process of simplifying complicated ideas and sharing them with a more general audience. Interpretation is much more than just rewording ideas though. Good interpretation should establish a connection between the audience and the object of interpretation. When used effectively, interpretation can even be persuasive. It can prompt people to make changes in their thinking and behavior. In some ways, interpretation is a lot like marketing. You have to understand your audience in order to be effective.

One of the main goals of environmental interpretation is to help humans understand the natural world. This helps them to form a positive, sustainable relationship with their environment. Interpretive programs can be targeted at any audience. They can be designed to meet specific needs. Interpretation can take the form of a simple, informative kiosk or nature walk. It can also be more complex. The promotion of a community based recycling program is an example.

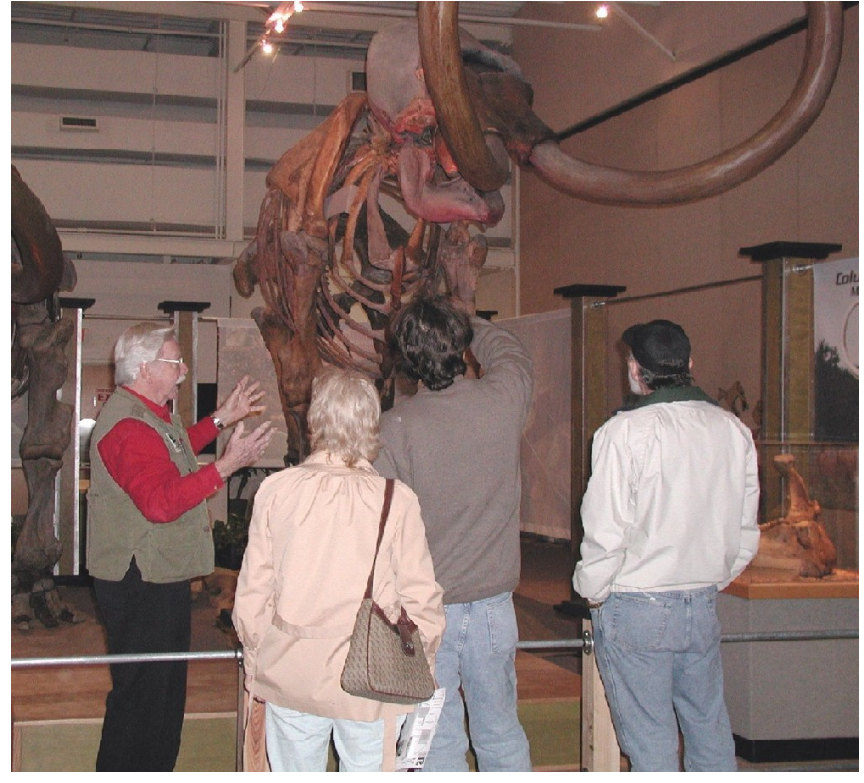

Figure 1. Museum docent, Pope Cheney, interpreting the "Tusks" exhibit at the University of Florida Museum of Natural History. This photograph was taken with the permission of museum personnel. Photo by Kara Youngentob.

This document will focus on how to target and communicate persuasively to your audience (Figure 1). The purpose of this document is to show you how to influence people's attitudes and behaviors. This

1. This document is WEC 169, one of a series of the Department of Wildlife Ecology and Conservation, Florida Cooperative Extension Services, Institute of Food and Agricultural Sciences, University of Florida. First published in November 2003. Please visit the EDIS Web site at http://edis.ifas.ufl.edu for more publications.

2. Kara N. Youngentob, Graduate Student and Wildlife Extension Assistant, Department of Wildlife Ecology and Conservation; Mark E. Hostetler, Assistant Professor and Wildlife Extension Specialist; Department of Wildlife Ecology and Conservation; Institute of Food and Agricultural Sciences (IFAS), Florida Cooperative Extension Services, University of Florida, Gainesville, Florida 32611.

The Institute of Food and Agricultural Sciences is an equal opportunity/affirmative action employer authorized to provide research, educational information and other services only to individuals and institutions that function without regard to race, color, sex, age, handicap, or national origin. For information on obtaining other extension publications, contact your county Cooperative Extension Service office. Florida Cooperative Extension Service/Institute of Food and Agricultural Sciences/University of Florida/Christine Taylor Waddill, Dean. 
document will not teach you how or when to use different modes of interpretation. Kiosks, brochures, and public talks are examples of interpretive modes. However, the information that you learn here can be combined with whatever mode(s) you choose.

\section{The Path to Effective Interpretation}

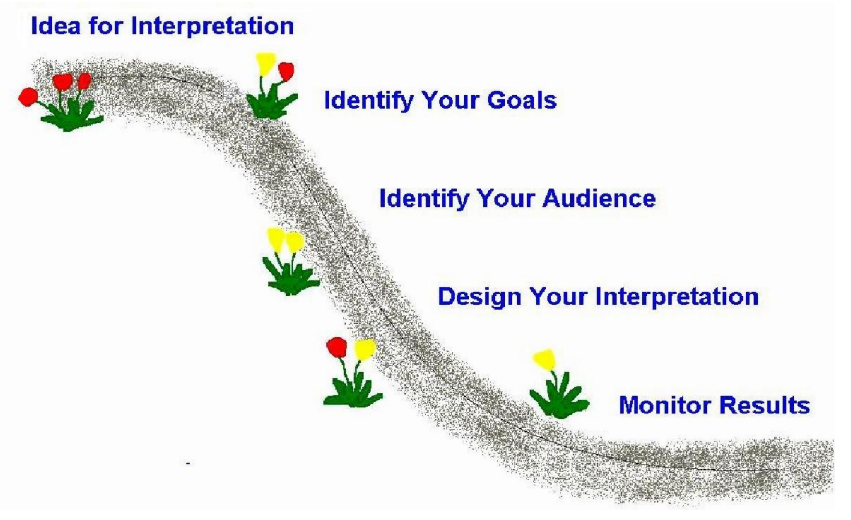

Figure 2. Interpretation road

There are several important steps to successful interpretation (Figure 2). First, think about the object or idea that you are interpreting. What do you want people to know or learn? What are your goals? Small goals are good. Small goals can be added together to achieve larger goals. What you want to interpret and your goals for that interpretation should be the first two things that you consider when designing your program. Next, identify your audience. Think about how you will present your interpretation to that audience. Try to incorporate some ways to obtain feedback on your efforts. This will help you to know if you are achieving your goal(s). Monitoring your program will also help you to adjust your interpretation so that it can be more effective.

\section{Audience Awareness}

Let's assume that you have already decided on your topic and your goals. Next, we need to think about the audience. You are likely to encounter a very diverse audience in your interpretation. Your audience can range in age, education, cultural background, and socio-economic status. On average, it is best to aim your interpretation to 8th to 10th grade reading levels. This range insures that you do not exceed the reading comprehension level your audience and that you are also not too simple. Several computer programs can provide you with an index of grade-level based on your wording. One example of this is the Flesch-Kincaide grade index. This particular index is based largely on sentence length and word length.

Interpretation can reach a wide range of people. As much as possible, you should tailor your interpretation to your audience. Understanding your audience is key. The socio-economic status of your audience is an important consideration. It impacts their lifestyle and daily concerns. These concerns will dominate how your audience relates to your interpretation. Most likely, your audiences will share a similar socio-economic status. In the United States, the majority of people fall into the socio-economic category of middle class. We will focus on middle class audiences for this article.

\section{Ideal Targets for Interpretation}

The middle class is an ideal target for environmental interpretation. Their economic standing provides them with the opportunity to consume vast amounts of resources and produce a lot of waste. The middle class also has the luxury to focus much of their attention on issues not immediately related to their survival. For example, people who are not impoverished are usually not concerned with starvation. Generally, they are not worried about death from exposure to the elements. Freedom from immediate survival pressures provides flexibility for adopting new behaviors. This dynamic is explained by Maslow's "Hierarchy of Needs Model" (Figure 3).

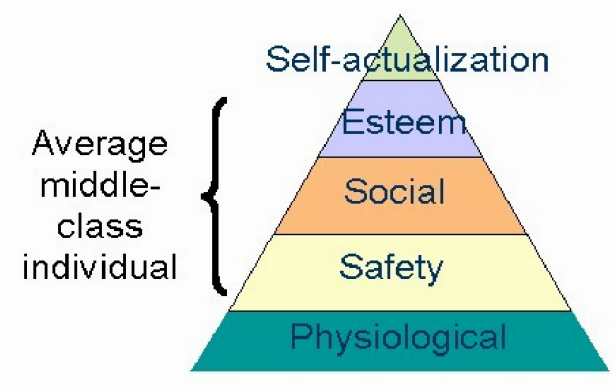

\section{Maslow's "Hierarchy of Needs"}

Figure 3. Maslow's Theory

Maslow's theory is illustrated with a triangle-shaped model. This model tells us what our 
primary concerns are. These concerns are based on where we lie on that triangle. According to Maslow's theory, we are all trying to work our way up to the top of this triangle.

Most people in the United States fall around the middle of Maslow's triangle. The model shows us that the middle class is above the concerns that represent immediate survival. Safety may remain a concern to some degree. The middle class is also looking to achieve social belonging and esteem. This means that interpretation methods and modes that connect people to their community and help them gain esteem from their peers will be very effective. Most people will also be interested in issues that can directly impact their ability to maintain those basic needs (food, shelter, and safety).

\section{Connecting the Audience to the Issue}

Where possible, all interpretive programs should focus on connecting the object or issue of interpretation to the audience. People are more likely to understand something to which they can relate. We are all more likely to have positive feelings towards things we understand. People will strive to find connections when presented with a new concept or idea. You can help direct this inclination so that your audience will form positive associations.

How do you help people relate to a particular animal or environment? Try to think of something that is familiar to people. Imagine a situation that they might encounter day to day. For example, maybe you want to teach someone about cardinals (Figure 4). You could tell a story about an individual cardinal's struggle to secure his own territory in the forest. You could explain the great lengths that this brightly colored male goes through just to attract females. This scenario matches people's desire to be successful and find mates of their own.

Another way to enable the forming of positive associations is through the use of anthropomorphism. Anthropomorphism is assigning human characteristics to non-human things, events, or animals. For example, beavers are sometimes drawn wearing construction helmets. A related sign might say, "Beavers are the architects of wetlands. Without their hard work, we would lose many of our natural

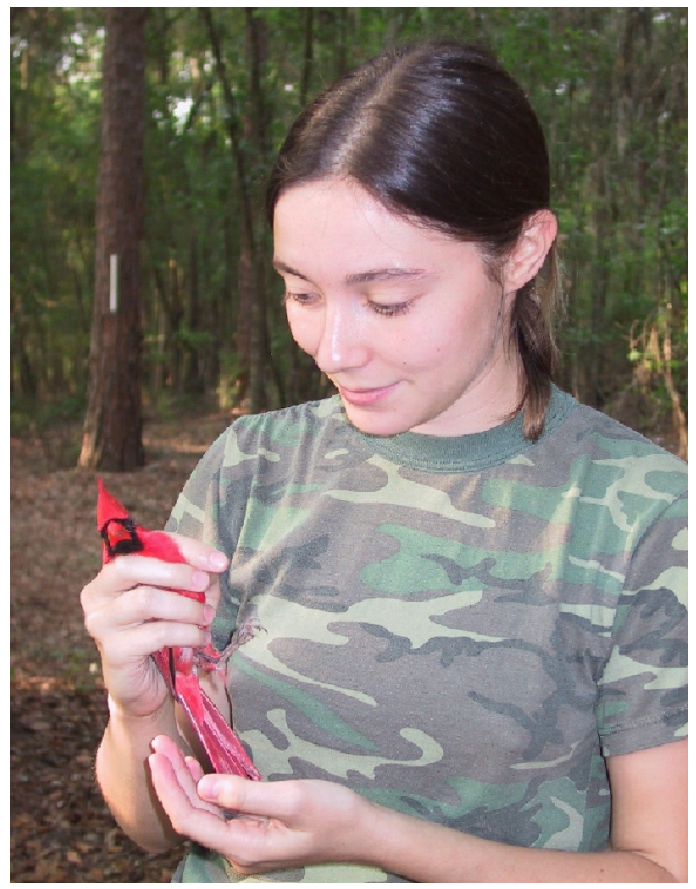

Figure 4. Bringing wildlife and wildlife issues to the public can be a rewarding experience. Wildlife graduate student, Kara Youngentob, holding a Northern Cardinal for instruction to a group of undergraduate students at Ordway Nature Preserve, Florida. Photo by Sarah W. Miller.

ponds." Referring to beavers as architects relates them to a human concept. An architect is a person with an important job that is familiar to most people. Metaphors like these can be very helpful. However, care must be taken not to overshadow or stifle reality. A wonderful aspect of nature is its amazing diversity. It is important to allow people to realize these differences too.

Most audiences also show particular interest in stories involving baby animals. Babies are a great way to get attention. People relate to babies since we have babies too. Most people have positive and even protective feelings towards babies. Additionally, people are usually captivated by amazing or frightening environments or events. These are another excellent way to capture attention. They speak to people's interest in insuring their own safety. Successful interpretation must capture the interest and emotion of the audience.

\section{Keep it Simple}

Your interpretation should be 'short and sweet.' Otherwise, people will quickly lose interest. If people 
are reading your interpretative materials, present the most important idea up front, on top, and in bigger letters. The fewer written words you use, the better. Try to make your message as simple as possible. Then make it simpler. Most people will only glance at a display or brochure. The general idea of your message needs to be communicated in those few seconds. You can afford to include a little more detail if you are giving an interpretive talk.

Themes should be used to tie interpretive materials together. Themes are especially useful if you have several displays or modes for one area. Themes help your information flow. This flow helps hold and direct people's attention. Another excellent rule of thumb for creating interpretive materials is Susan Jacobson's ABCDs of interpretive design. The $\mathrm{ABCD}$ refer to "attractive, brief, clear, and dynamic."

\section{The Power of Words}

The way that you use words can have an enormous impact on your audience. You should use active voice and not passive in your interpretation. Try to use active, colorful, and descriptive verbiage. What you say and the way you say things can influence the behavior of your audience. One very good way to be persuasive is through the use of injunctive norms.

Injunctive norms express how the majority of people feel about a certain issue. For example, "Most people think that wasting water is bad." This is an injunctive norm. Injunctive norms take advantage of peoples need to conform. People will change their behaviors to reflect what they perceive that other people in their community are doing. They will make these changes based simply on what they are told about how the others feel. This will work even if the majority of people are actually wasting water, as long as the only information that you present is that a lot of people think that wasting water is bad.

Descriptive norms are the opposite of injunctive norms. Descriptive norms describe what is done rather than what should be done. Descriptive norms describe the actual behavior of the majority. It is important not to use descriptive norms in interpretive materials if the norms do not reflect the desired behavior. For example, the statement, "More than half of all Americans leave their lights on when they are not home; this wastes limited natural resources," is not an effective deterrent to this behavior. Even though your audience might know that this behavior is not "good," you are telling them that the majority still do it. People in general are strong conformists. People are less likely to change their behavior if they feel like they are the only ones changing. They will continue leaving their lights on because everyone else is too.

When you are designing your interpretation, think about what makes good advertising successful. People are easily influenced by what they see other people doing. If people see a lot of litter on the ground, they are more likely to litter too. The reverse is true also. As tempting as it may be, avoid telling people how much "everyone" is harming the environment because of $\mathrm{x}, \mathrm{y}$, and $\mathrm{z}$. This is not a good strategy for changing behavior. More and more environmental interpreters are realizing the importance of avoiding these descriptive norms. You can still explain that a particular activity is happening. You can explain that this activity harms us and our earth. Just do not imply that participating in this harmful activity is the social norm.

\section{Model Appropriate Behavior}

You now know how to successfully use the power of the majority to your advantage. This sets the stage for change to happen. The next step is to provide alternatives. It is easier for people to change behaviors than just stop altogether. Whenever possible, you should model the appropriate behavior yourself. This is also a good opportunity to present your audience with 'win-win' scenarios. For example, "Changing $\mathrm{X}$ behavior benefits you by making your water safer. This will also help protect your local wildlife. Not changing could cost all of us our good health."

It may be more effective to emphasize loss over savings. People are more likely to change their behavior if they feel like their current behavior is costing them something. For example, "Leaving the water running while brushing your teeth costs you about X amount of dollars every month." This is much more effective than saying, "Turning the faucet 
off while brushing will save you money." Money or resources lost are real losses. Their loss was not anticipated. In the same vein, money or resources saved do not really count. They would have been spent anyway.

\section{Empower Your Audience}

Interpretation should strive to instill a sense of ownership. Ideally, your audience should feel like they are a stakeholder in whatever you are interpreting. For example, "Harm that comes to your local spring could also cost you your health, your recreational resources, etc."

It is very simple to imply ownership. Just relate to the place or object as "theirs." This method is particularly effective if you can stress that something has been established or protected for a long time. This dynamic can strengthen their desire to maintain their protective stewardship. People tend to resist change. The longer that something has been around, the more likely people are to want it to stay that way.

It is important that people feel empowered to take action. A good way to accomplish this is through instilling the sense of ownership mentioned above. People tend to feel like they have more control over their own belongings. Your audience needs to know that their actions do make a difference.

The amount of power people feel that they have over their own lives and their behaviors relates directly to how strongly they feel connected to their community. You can help people feel more empowered. You can provide outlets for social interaction in your interpretive plan. Empowerment and community go hand in hand. Ultimately this is what the middle class is striving for anyway. Simply telling people what is going on in their community helps them feel connected to it. Highlight potentials for them to get involved. Successful leadership opportunities provide esteem, recognition, and self-satisfaction. It is important, though, for people not to feel like they will be caring the torch alone.

\section{Bringing the Message Home}

Most people will be attracted to things that have an element of community (Figure 5). Encourage interactions between people. These actions can be centered around your interpretive goal. You could create a community oriented web site or newsletter. People like to have a place to share their comments or concerns. Find ways for people to volunteer their time in a public way that can be seen and appreciated by their peers. People desire recognition and interaction.

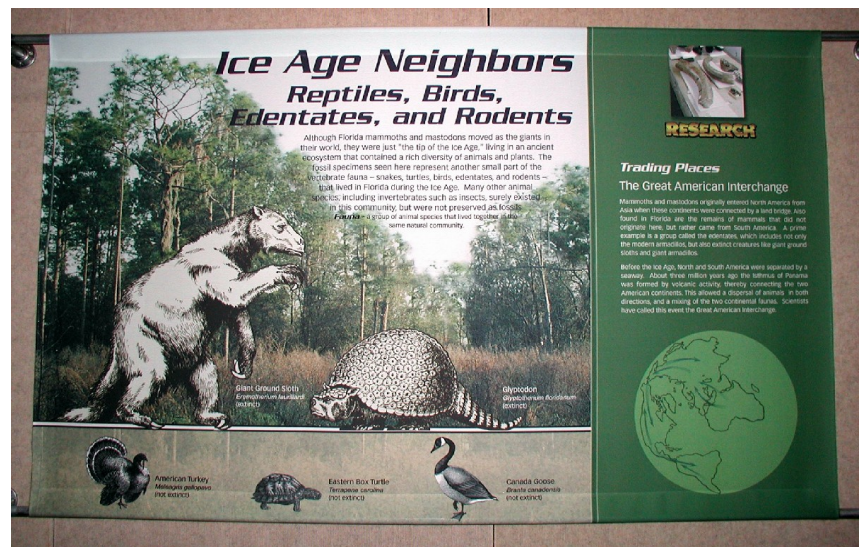

Figure 5. This sign appeals to people's interest in community. This panel is part of the "Tusks" exhibit at the University of Florida Museum of Natural History and was photographed with the permission of museum personnel. Photo by Kara Youngentob.

Getting people involved is also a good way to foster social diffusion. Social diffusion is the process of moving information from one person to another. Social diffusion is important. It allows your message to travel much farther than it would otherwise. Also, your message will be more solidified in a person who can teach it to another.

People seek the esteem and recognition of other people. Provide this recognition. This is an excellent way to increase participation in a desired behavior. If you are giving an interpretive talk, you could simply provide opportunities for people to correctly answer questions. Then offer praise. Sending personalized award certificates, posting the names of people on community boards who have recycled the most paper or planted the most native plants, or submitting newspaper articles about these people, are all excellent ways to provide the social esteem that people want. Publicity can also promote the image that this desirable behavior is the social norm. This reinforces the behavior in people who are already doing it too. 
In extreme circumstances, it can also be effective to publicly post the names of people who are participating in undesirable behaviors. You should never offer information that is not available in public records. It is always preferable to focus on the positive. The reverse strategy can have its time and place though. No one wants their community to look on them in a bad way.

The University of Florida Wildlife Extension Service has several programs that encourage people to take part in their communities. The Wildlife Habitat Evaluation Program (WHEP) and The Backyard Wildlife Habitat Program are two such programs. Participants are encouraged to teach others in their community about wildlife issues. These programs also provide certificates or awards to the people who complete them. You can find more detailed information on both of these programs and others at http://www.wec.ufl.edu/extension/

\section{The Importance of Feedback}

Feedback can be very helpful. Feedback can work as positive reinforcement. It lets people know that they are accomplishing something. It also adds to their sense of empowerment. Your audience can see how their actions really do make a difference. In addition, feedback provides a way to set long-term goals. Long-term goals and planning are necessary for most change to take place on a grand scale. You should also obtain feedback to accurately assess the success of your interpretive plan. In this way, appropriate changes can be made to make your plan more effective. Monitoring will help you know if you are achieving your goals.

Interpretation is a powerful tool when used wisely. Remember, interpretation that is based on "information only" is not the most effective way to alter people's attitudes and behaviors. Understanding and connecting with your audience is key (Figure 6).

\section{References and Further Readings}

Byers, Bruce A. 1996. Understanding and Influencing Behaviors in Conservation and Natural Resources Management. African Biodiversity Series, No. 4. Washington, D.C.: Biodiversity Support Program.

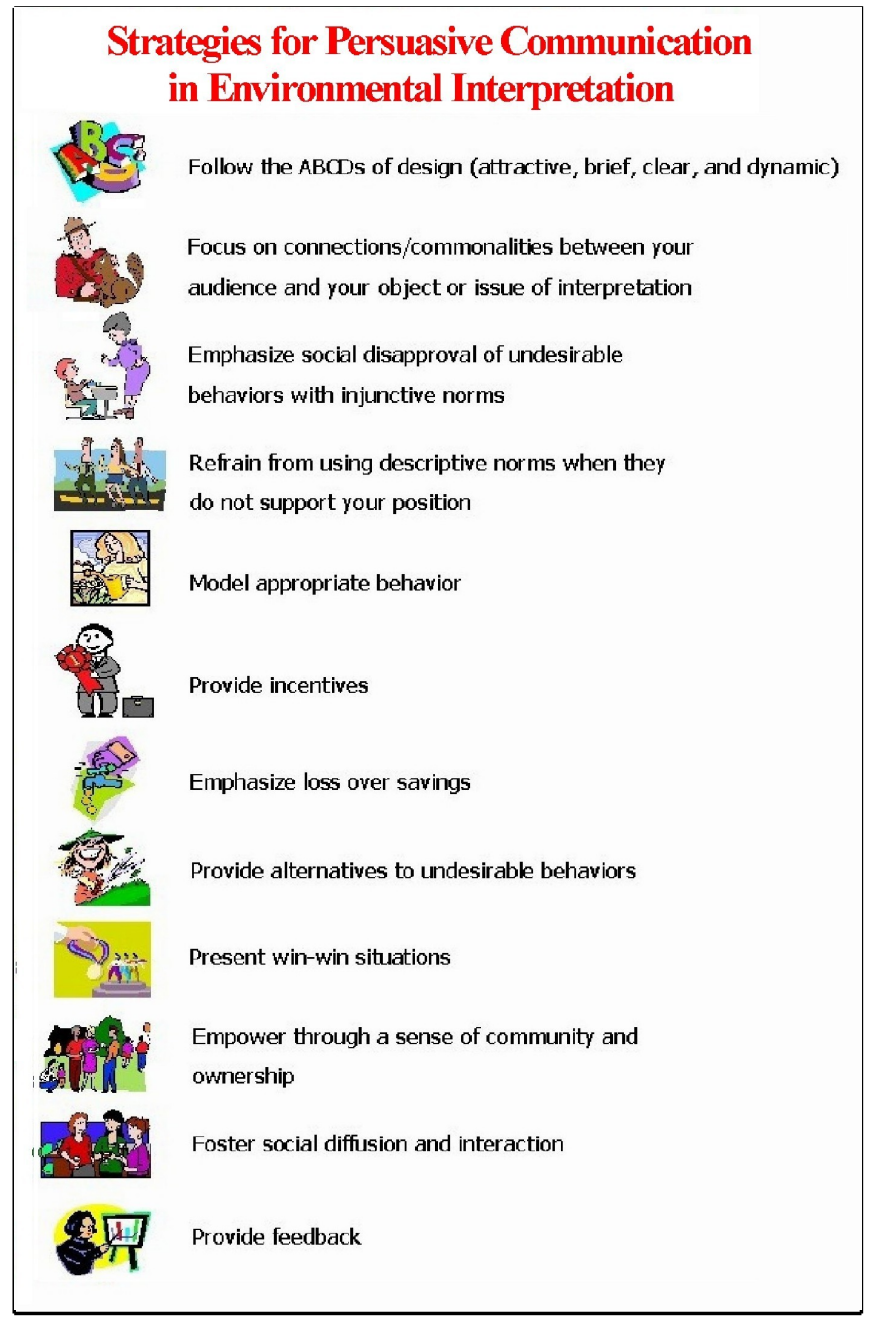

Figure 6. This is a brief overview of the strategies for interpreting the environment with illustrations. You can enlarge the image and then print it for use as a quick reference guide. Image created by Kara Youngentob.

Cable, T. T., and D. M. Knudson. 1983. Interpretation as a management tool--the manager's view. Proceedings of the 1983 National Association of Interpreters Workshop: Advances in Interpretation. West Lafayette, Indiana.

Cialdni, R.B. 1996. Activating and aligning two kinds of norms in persuasive communications. Journal of Interpretation Research 1(1): 3-9.

Hungerford, Harold R. 1996. The development of responsible environmental citizenship: a critical challenge. Journal of Interpretation Research 1(1): 25-37.

Jacobson, S. 1999. Communication Skills for Conservation Professionals. Island Press, Covela, CA. 
Maslow, A. H. 1954. Motivation and Personality.

Harper and Row, New York.

McKenzie-Mohr, D., and W. Smith. 1999.

Fostering Sustainable Behavior. New Society

Publishers, Canada. Chapter 6. pp. 82-102.

Tilden, F. 1977. Interpreting Our Heritage, 3rd ed. University of North Carolina Press, Chapel Hill. 